\title{
Personal characteristics of effective managers in organizational cultures of different types
}

\author{
Lyudmila N. Zakharova*, Elena V. Korobeynikova \\ Lobachevsky Nizhny Novgorod State University \\ *Corresponding author. E-mail: zlnnnov@mail.ru
}

Since the 1990s Russian enterprises have been experiencing difficulties in transitioning to the market-innovative model of development. In the context of the current variability of management paradigms, we had an opportunity to study the internal and external regulators of organizational changes that are typical for a transitioning economy. Organizational culture (OC) was studied as an external factor, while the personal traits of middle managers were viewed as internal factors because these managers are the agents for values and for behavior models, from corporate directives to "front-desk" personnel. The goal of this theoretical and empirical study was to determine the personality traits of middle managers who were deemed effective by top management in companies transitioning to the market-innovative model of development in the context of different types of OCs.

During the preliminary stage, we conducted a comparative analysis of the requirements for the personal traits of middle managers who are working in stable conditions as well as in conditions of transfer to the market-innovative model of development, and we selected the relevant methods of empirical research. During the first stage of the empirical part of our research we defined a group of four enterprises with OCs of different types, identified their effective mid-level managers based on expert evaluations by the top leadership, and formed test groups. During the second stage we studied the personal characteristics of these managers.

We determined that the personality traits of managers deemed effective by their leaders form integral complexes, which in turn correlate in a certain way with the type of OC of an enterprise. We identified four models of an effective manager: Mentor, Dictator, Innovator, and Businessman; these managers have varying degrees of work productivity, value priorities in the development of OC, personal self-concepts, organizational leadership skills, and types of decision-making. It has been demonstrated that in the evaluation of the effectiveness of a manager of an enterprise, the correspondence of his/her personal traits to the characteristics of the OC prevailing in the company is a more important factor than his/her agreement with the long-term goals of the company and, therefore, with the more promising type of OC. This phenomenon opens a way to utilize such functions of OC as internal integration but prevents external adaptation, which in turn becomes a serious psychological obstacle in the development of an enterprise. 
The OC of an enterprise has a powerful potential to attract employees with certain sets of psychological traits. Important tasks for the psychological support of the organizational development of an enterprise could be the development of a criteria database for the evaluation of managers and the development of a management talent pool based on the market-innovative vector of development of an enterprise with relevant changes in the OC.

Keywords: transition economy, innovations, psychological regulation of activities, organizational culture, values, managers' psychological characteristics

\section{Introduction}

Since the 1990s Russian society has been involved in global transformation processes and has been undergoing considerable changes connected with the realization of market principles in the economy, with the modernization of enterprises, and with their transition to the innovation format of development. On the level of specific enterprises, constantly ongoing organizational changes have replaced stagnation. However, modernization processes are slow and contradictory, as is well known. In 2012 at the investment forum "Russia Calling!" V. Putin noted better and more balanced growth was noted in comparison with the period before the crisis (Putin, 2012). Nevertheless, innovative development is lagging so much that the idea of making innovations obligatory was seriously discussed.

On September 27, 2013, Russian Prime Minister D. Medvedev published a policy article, "The time of easy decisions has passed," in the newspaper Vedomosti (Medvedev, 2013). He wrote that, "at present, unfortunately, nearly every project faces a recruitment problem - who will work there? Is the average Russian ready to meet modern labor market requirements? We know the answer, and that answer is more often no than yes". In a speech at the 2014 "Russia Calling!" forum the Russian President V. Putin remarked that Russia was still lagging behind the EU countries in labor productivity and called maintaining nonefficient workplaces "a way to nowhere" (Putin, 2014). Thus it was again underlined that the undertaken efforts regarding innovative development had not yet led to the expected effect.

Analyzing the causes of the problems, experts (Glazjev, 2007; Kudrin, 2014; Gubanov, 2015) agree that the discrepancy between management quality and reaching set goals is one of the major reasons. A key step on the way to this problem's solution is creation an integral system for the modernization and reproduction of professional elite of effective managers (Medvedev, 2007). Set in 2007 this goal is still relevant.

Psychological science has its own role in solving the complex problems entailed in enhancing the management of the transition economy. These problems include, in particular, the scientific grounds for the process of modernizing managerial resources. While solving this problem, it is necessary to answer this question: Do different organizational conditions require special psychological characteristics of managers or will a manager having specific psychological characteristics be effective under any organizational conditions that correspond to different types of economic relations? This question shows that the goal of detecting the psychological grounds for management enhancement goes beyond applied psychology because achievement of this goal opens up opportunities for deepening scientific beliefs 
concerning the role of external and internal factors in the regulation of work, as exemplified by managerial work.

Much research that reveals the peculiarities of an effective manager's personality has been conducted (by, for example, W. Bennis, A. V. Filippov, A. I. Kitov, A. G. Kovalev, E. G. Mall, B. Nanus, B. D. Parygin, K. K. Platonov, V. F. Rubakhin, R. H. Shakurov, R. Strogdill, A. L. Sventsitskiy, L. I. Umanskiy, A. L. Zhuravlev). Descriptions have been given of leaders' individual psychological qualities, from motivation and cognitive abilities to commitment to moral values. Managerial problems have become so acute that the introduction of what is called transformational leadership seems logical (Bass, 1998, 2006; Hannah, 2014). The importance of these data can hardly be overestimated because they reveal the psychological characteristics of managers that make it possible for them to achieve goals effectively during transformational processes (Carter, 2013).

Russian research almost always lacks an analysis of the peculiarities of the transition economy and the qualities required of managers. The peculiarity of most foreign research is that the important data are limited in that they are obtained from the United States and Western Europe, which at the time of the research already had established market economies and the traditional susceptibility to innovations. Managers' training all over the world almost always is based on the results of this Western research.

The fact that external conditions influence managers' efficiency is admitted by almost all researchers of managerial behavior. Confirming the well-known ideas of S. L. Rubinshtein about the deflection of the external through the internal, at present the scientific community agrees that "an individual should be studied in context, including the organizational one" (Guimond, 2004, p. 488). Emphasizing the complex relations between individual personality traits and work productivity, Schmitt (2014) demonstrates the importance of the influence of the context mediating this relationship. The most significant research consists of studies of organizational cultures (OCs) because it presents the organizational and at the same time the socialpsychological context in which work and managerial behavior are realized. As one of the proponents of organizational-cultural research, Schein (1992), said, OC contains the mindsets, values, behavioral patterns, and expectations of the organization's members. While an organization's strategy tells employees what they should be doing, the OC defines how they should do it (Driving Global, 2006, p. 2).

In the context of organizational changes, when the preferred OC has not yet been formed, the management team finds itself in quite a difficult situation. First, in the midst of fundamental changes, with the proper management in place, employees, as internal social capital, turn out to have more potential than staff hired from the outside (Cuevas-Rodríguez, 2014). Second, staff members have a stronger view of managers as their leaders when the managers are introducing obvious positive improvements (Mumford, 2014), while the transition-to-innovation model of development is accompanied by complex psychological costs that cause deep negative experiences (Zakharova, 2010). However, the current challenges have to be addressed, and management often chooses the familiar way by enhancing the administrative component and increasing hierarchical dominance, thereby distancing itself from the market-innovation model. Employees continue to work, forming the new relations between the conflicting goals: those that are genuine and 
those that are proposed by managers (Unsworth, 2014); the organizational situation remains stable or undergoes minor changes. The role of OC in achieving the commitment of personnel and organizational efficiency is also underlined by Russian researchers (Dryakhlov, 2011; Dyrin, 2006; Leonova, 2013; Morgunov, 2010; Zakharova, 2009, 2010, 2012).

Among the works on OC a special place is held by the cross-cultural research of Hofstede (1991) and by the study of enterprises' OC by Cameron and Quinn (1999). The research of Hofstede showed that the manifestation of managers' individual psychological peculiarities in their managerial behavioral style depends on ethnocultural factors. Analysis of Cameron and Quinn's model makes it possible to see the basic value differences in the main types of OCs. The identification of the value grounds of an OC is of critical significance for a psychological behavior analysis because the values act as basic regulators. Individual values are usually described as objects in the environment that people work for or desire (Locke, 1976), and organizational values are usually described as the things an organization must do in order to survive and thrive (Tosti, 2005). Therefore, values have consequences for behavior (Herbst, 2009). Cameron and Quinn showed convincingly that each type of OC eventually attracts managers with specific types of values and determines the manifestation of the individual psychological peculiarities of personnel, including managerial peculiarities in the format of the behavioral model of the specific type of OC.

The results of the research conducted in developed economies do not make it possible to answer the questions that are relevant for economies in transition. In conditions of real market relations, economic self-regulation processes touch on the organizational cultural characteristics of enterprises. And if an enterprise's management encourages the development of an OC that does not meet the challenges of the competitive environment, of the specific business, and of the enterprise's resource potential, then the enterprise will decrease its market presence. In a system of nonmarket relations, the enterprise can maintain its position by means of other factors: for example, government support, internal market protection. Therefore, an OC that is not efficient in the relevant market conditions may be present in an enterprise in an economy in transition for an indefinite period of time.

Currently, Russia is in the process of transitioning from the administrativecommand model to the market and innovative model of economic development. Based on the theory of organizational development, it can be reasonably supposed that this transition will be accompanied by a corresponding change in the socialpsychological context of the organizational processes that are represented by the enterprises' OCs. Being a powerful influence on human behavior, an OC forms and maintains patterns of behavior leading either to achievement of organizational goals or to serious risks. And, indeed, research confirms that managers consider the transition from the hierarchic-clan OC to the market-adhocracy OC to be the main vector of organizational cultural development (Dyrin, 2006; Zakharova, 2008,2010 ). At the present moment many Russian managers, facing new economic relations, have started to believe in the significance of OC and to include the modernization of $\mathrm{OC}$ in the list of their enterprises' development goals. In addition, the model of the hierarchic-clan OC remains typical of enterprises having difficulties with modernization, and these models vary little from the socialistic model of human resource management (Dyrin, 2006; Zakharova, 2008, 2010). As Diamond 


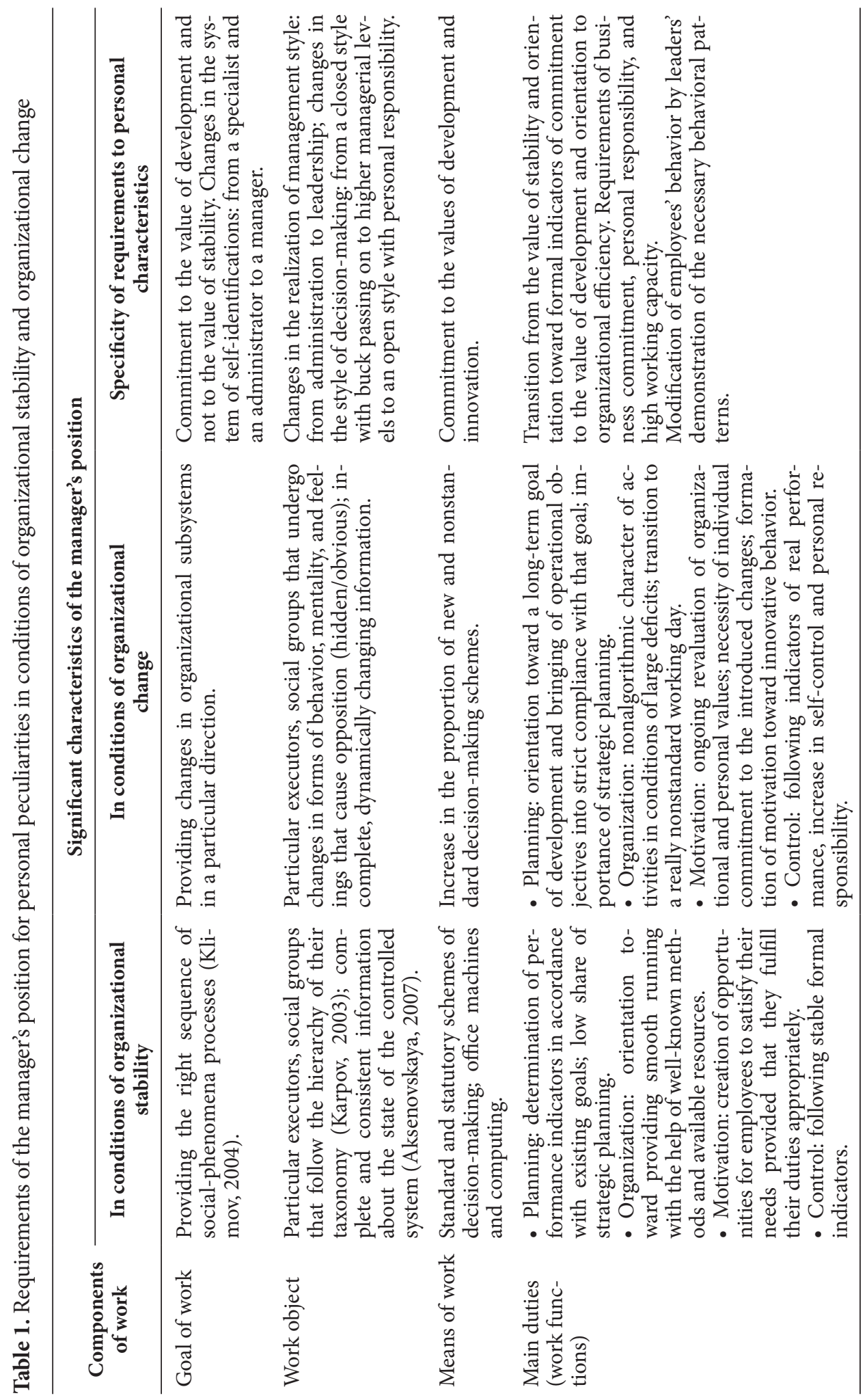


(1996) remarks, hierarchical OCs are unintentionally constructed on the model of psychological defenses, of what might be called externalized ego defenses. This model indicates strong resistance to innovations that might break the feelings of self-protection and self-confidence inherent in this culture.

It is typical for the management of such enterprises to accept the external requirements of the market and of innovative development in accordance with the modern political and economic situation. However, these requirements do not become the goals that really regulate business activities. That is why, as noted by the Russian president, the majority of enterprises demonstrate organizational cultural nondevelopment, which holds back their progress (Putin, 2012).

Thus, on the one hand, both the society in general and the enterprises' management, as the key professional group, admit the necessity of enhancing management for the sake of economic modernization. On the other hand, the research results focus on the search for an optimal combination of organizational conditions and personal characteristics of managers fulfilling the goals of modernization.

The solution to this problem presupposes study of the psychological determination of the efficiency of the renewal of managerial personnel with regard to the environmental component that is manifested in the form of peculiarities of OC and to the subjective component, in which the manager's personality is the central element. Analysis shows that organizational changes necessitated by the marketinnovation model of development impose fundamentally different requirements for the manager's psychological profile (Table 1): from work efficiency to values.

In the context of the multiparadigm nature of management and the variability of organizational cultures (Dyrin, 2006), the relevant question is How inherent are the identified personality traits to intermediate-level managers? Intermediate-level managers are of particular research interest as they are or should be the agents of corporate policies of market-innovative development and should be exercising managerial influence on their subordinates.

We conducted a study aimed at identifying the personality traits of middle managers working in enterprises with different types of OCs; the managers were recognized by their leadership as being effective during the transition of enterprises to the market-innovative model of development.

\section{Method}

The empirical part of the research was carried out in two stages. During the first stage, we identified the types of OCs of 16 enterprises, then selected 4 of them with the most distinct types of $\mathrm{OC}$ and defined the vector of transition to the marketinnovation development model. The following methods were used:

- Analysis of corporate documentation (we analyzed the organization's mission and strategic goals, code of business conduct, personnel policy, development programs, quality policy, staff incentive policy, professional-development policy, collective-bargaining agreements, etc.).

- Expert evaluation (our experts were five top managers from every studied organization and five experts from the Organizational Consulting Center of Lobachevsky Nizhny Novgorod State University). 
- The Organizational Culture Assessment Instrument created by Cameron and Quinn (1999); this method is interesting because it allowed us not only to highlight the value of managers in (MSAI) OC based on the relative importance to them of relations (clan component), innovativeness (adhocracy component), achieving success in a competitive environment (market component), and order (hierarchical component).

- Mathematical statistics: using the Wilcoxon signed-rank test (T test) we determined the significance of the domination of a particular type of OC in the studied enterprises. The results were processed using the SPSS 15.0 software package

As a result of the first stage, we used the expert evaluation to select the effective middle managers from the four selected enterprises. We used the Management Skills Assessment Instrument of Cameron and Quinn (1999), which allowed us to assess a profile of skills in different areas of management activity (effectiveness of goal-setting, planning, control, motivation, awareness of goals, focus on the customer, organizational skills, leadership, credibility, general awareness, delegation of responsibilities, respectfulness, level of culture, self-control, resourcefulness, determination, acceptance of innovations, perception of criticism, persistence).

During the second stage of the empirical part of our research, we identified the personal characteristics of the middle managers selected during the first stage. The total sample was 120 middle managers (30 people from each enterprise). Subjects from different enterprises were balanced by gender and age and their level of technical and technological competence.

At this stage, we used the following methods and specific methodologies:

- Assessment center, in which we conducted the study of observable manifestations of situational leadership in the middle managers in individual and team work.

- Psychodiagnostic method: Kuhn and McPartland's Twenty Statements Test (1954), a spontaneous self-concept test that allowed us to get a set of free - i.e., not connected to the questionnaire - objective and subjective self-concepts by having the test subjects answer such questions as "Who am I now?" and "Who am I in 5 years?" The responses are organized in groups of five self-concepts (family, professional, civil, private, other). We also used the method of Conflict Situations by Zakharova (2008), which is built on self-and counter-identification of subjects in situations of internal conflict. The set of situations used in this assessment allowed us to estimate the dominating value regulators of a manager's behavior (achieving the result, maintaining relations, morality, or creativity), the key parameters of decision-making (responsibility/irresponsibility, openness/dissimulation), the managerial stereotypes used in making and implementing decisions (stereotype of mistrust, dominance of family roles, administrative dominants). In addition we used methods of computer laterometry by Shcherbakov, Sheromova, Polevaya, and Parenko (2003), based on a study of the hemispheric sensory (hearing) asymmetry of the brain, and the Psychomotor Vigilance test of E. Landolt (Sisoev, 2003), which allowed us to assess 
the work performance of a manager: productivity, endurance, precision, reliability.

- Mathematical statistics: we used the Wilcoxon T test and Spearman's rank correlation coefficient $r$; processing of results was carried out using the SPSS 15.0. software package.

\section{Results and discussion}

The following are the data for the four enterprises with the following types of OC: clan-hierarchical, hierarchical, adhocratic with market elements, market-hierarchical. The goals for the institutional development of all the enterprises included transition to a market-innovation development model.

We discovered that in the four enterprises selected during the first stage, with a fundamental vector of transition to the market-innovative development model, the personality traits of effective managers form coherent complexes (the psychological models of successful managers). They are in a way consistent with the dominant type of OC. The study identified and characterized four qualitatively unique sets of personal characteristics of the managers who were effective in specific types of OCs (Table 2).

Each of the detected types of the Psychological Model of the Effective Manager has its own peculiar features.

The psychological model type Mentor, characteristic of the clan and clan-hierarchical OC. The domination of the value of relations maintenance was detected $\left(\mathrm{T}_{\mathrm{EMP}}=59.5 ; p<0.01\right)$; the value of morality ranked second. These managers are sure that fulfillment of their moral duties contributes to the maintenance of benevolent relations with employees of different status. Both family and professional roles dominated within their social self-identification in both their current and their long-term assessment (34.4\% and 35.3\%, respectively). This finding proves the influence of stereotypes brought from family life to professional activity. The qualitative analysis showed the absence of dynamics in the self-identifications; in other words, these managers neither strive for changes nor see any possible directions for doing so. Most of their managerial decisions are open, but they have a very low level of responsibility. They seek to reveal their position, but they shift the responsibility for their decisions on others. In addition, higher results on this index were revealed in family interaction than in professional interaction $\left(\mathrm{T}_{\mathrm{EMP}}=18.3\right.$; $p<0.01)$. This is a typical attribute for the stereotype of "family-role dominance" (Zakharova, 2008). These managers gave a low estimation of their leadership qualities in comparison with the estimation from the expert assessment $\left(\mathrm{T}_{\mathrm{EMP}}=109.0\right.$; $p<0.01$ ); this discrepancy is explained by the absence of any demand for the manifestation of leadership in the clan and clan-hierarchical OC. Their average working capacity was medium, as manifested by their absence of enthusiasm and their slacking in work. Among their main working-capacity characteristics was their average level of endurance and reliability against the low level of their work accuracy and productivity.

The psychological model type Dictator, characteristic of the bureaucratic OC. Domination of the value of achieving a stable result $\left(\mathrm{T}_{\mathrm{EMP}}=76.5 ; p<0.01\right)$ was detected; the value of maintaining formal relations following the subordination- 


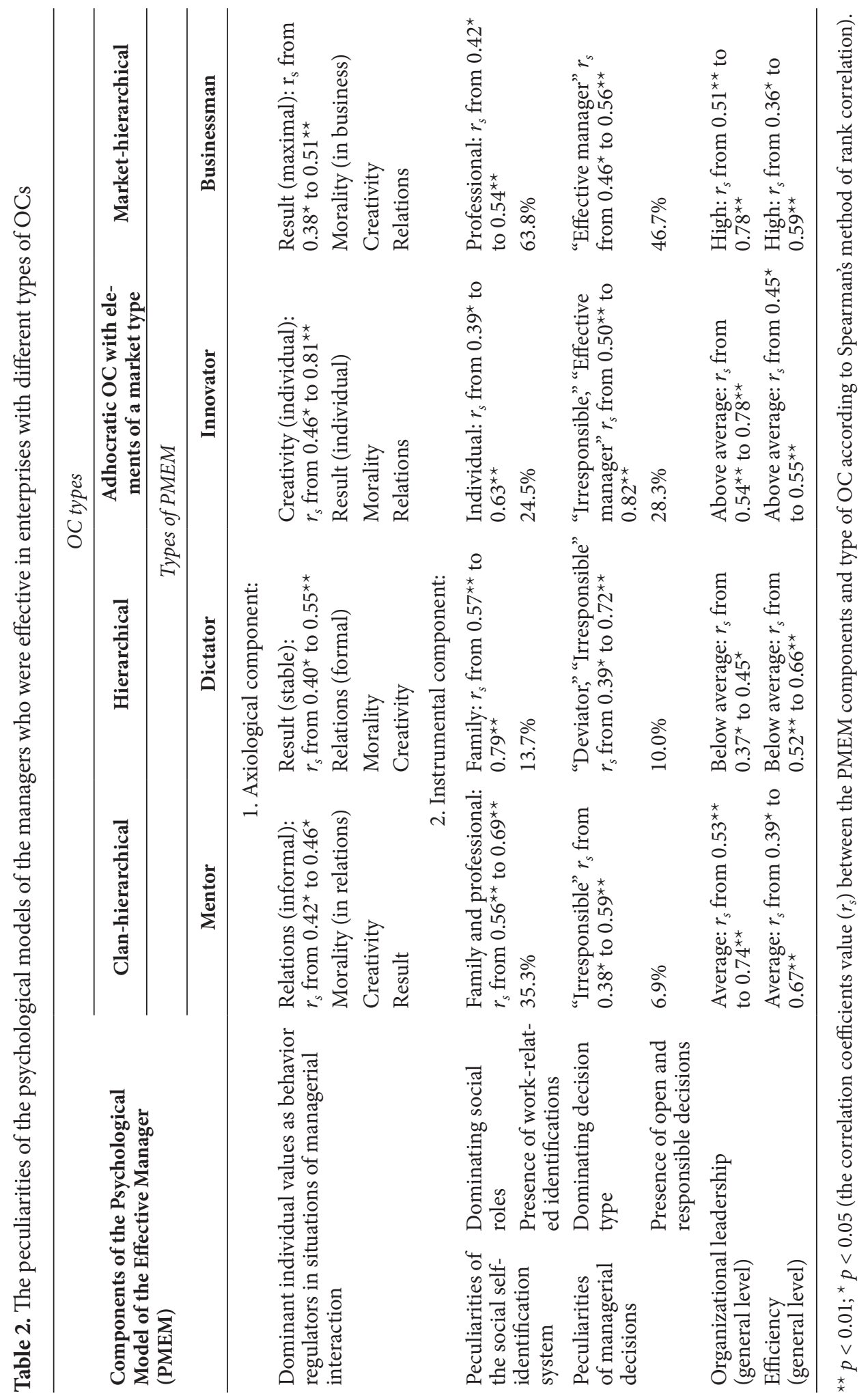


submission type was second. The system of social self-identification revealed that family roles are more typical for these managers than are their professional roles (32.5\% against $14.6 \%)$; the same results were obtained for the perspective of 5 years $(27.4 \%$ against $12.8 \%)$. These results indicate the possible future impossibility of a competent specialist taking any responsibility. These managers did not expect open and responsible decisions from their interaction partners (in $53.3 \%$ of cases), a finding that shows the manifestation of the distrust stereotype (Zakharova, 2008). In addition, the signs of the administrative-dominance stereotype were found; this stereotype is manifested in a closed position and in a desire to avoid any responsibility. Further on, a low level of development of leadership qualities was detected (expert assessment $-37.4 \%$ of the maximum possible level; selfassessment - 38.6\%). In most of the business games (in the assessment center) these managers' leadership had a situational character. Their efficiency at work was assessed at the lower-than-average level, including average productivity and accuracy and low endurance and reliability. Such a combination of parameters proves the orientation of these managers toward error-free work. During the working day their general efficiency on subjective and psychophysiological levels decreased, a sign of an unfavorable influence on a manager's organism in the conditions of a bureaucratic OC.

The psychological model type Innovator, characteristic of the adhocratic OC with elements of the market type. The value of creativity $\left(\mathrm{T}_{\mathrm{EMP}}=131.5, p<0.05\right)$ dominated in the hierarchy of these managers' individual values. Second place was taken by the value of achieving an individual result. To accomplish their personal goals such managers tend to show maximum energy and vigor, but at the same time they can disregard not only some interpersonal relationships but also a number of moral principles. In the actual and potential systems of social self-identification the roles of private individuals dominated $(47.7 \%, 45.2 \%$, respectively); these are roles that are important for self-recognition, finding the right place in the world. The majority of the decisions of these managers showed a high level of openness and responsibility, especially in professional interactions. The personal decisions made by the managers in the adhocratic OC were more effective than the decisions they expected from their interaction partners $\left(\mathrm{T}_{\mathrm{EMP}}=94.0 ; p<0.01\right)$. But many highly open and responsible decisions make it possible to speak about the managers' inclination to manifest a distrust stereotype (especially in conflict situations, actualizing the value of creativity) and also about insignificant disharmony in the analyzed characteristics of the managerial decisions. Leadership qualities exhibited in the assessment center were determined to be higher than average $(77.1 \%$ of the maximum possible). Such leadership bears a personal character. The working capacity of these managers was higher than average (for $73.3 \%$ of the managers). It was manifested in the high accuracy and reliability of their work, their higher than average endurance, and their average productivity. Therefore, for a manager in an adhocratic OC it is important to maintain the target level of efficiency for a long period of time. In addition, the rates showed improvement of mood during the day; this improvment was reflected on the psychophysiological level. The obtained results are regarded as a sign of the mobilization of the psychological and psychophysiological reserves of these managers and, in general, indicate the favorable influence of work activities on the organism of employees in an adhocratic OC. 
The psychological model type Businessman, characteristic of the market-hierarchical $O C$. The prevalence of the value of achieving a result, a group result in particular, was detected $\left(\mathrm{T}_{\mathrm{EMP}}=121.5 ; p<0.05\right)$. The value of business morality was in second place; it places great significance on the quality of the completed workand on following existing norms. The system of social self-identification showed the dominance of professional roles ("now" $-62.8 \%$, "in 5 years" $-64.9 \%$ ); the percentage of family roles was considerably smaller (11.7\%, 7.0\%, respectively). High results were also shown in decision-making: the decisions of $46.7 \%$ of these managers were highly responsible and open. From their interaction partners they expected highly open decisions in $38.3 \%$ of the cases and highly responsible decisions in $55.0 \%$ of the cases. These results show that managers effective in a market OC tend to avoid the stereotypes of distrust, family, and administrative dominance. The majority of members of this group (88.6\%) also showed high leadership qualities; in this, as in the previous, case, no significant differences between the expert assessment and the self-assessment were found. As for leadership, it bore a personal character. A high level of working capacity was established, including high productivity (53.3\% of the managers), a high level of endurance (60.0\%), a high level of accuracy $(70.0 \%)$, and higher-than-average reliability (73.3\%). These results indicate these managers' strong will power and internal self-discipline. During a working day quite a stable high working-capacity level was shown both on the subjective and on the psychophysiological levels; this finding makes it possible to speak about the favorable influence of work on managers working in the market OC.

Thus, the results show that in OCs of different types successful mid-level managers possess specific complexes of psychological characteristics. Two facts are the most interesting. The first one is that, according to the top-management assessment, nonefficient enterprises have managers who are assessed as successful although they cannot deal with the problem of propelling the enterprise to the necessary level of development. This fact proves that these managers are perceived positively and, therefore, that nonmarket values lying at the base of the assessment turn out to be stronger than the enterprise's efficiency. The second fact is that during the research period personnel rotations took place at the enterprises considered most efficient among the four being studied, but in no instance were all the employees replaced.

If the conditions for achieving high work results are analyzed, it is clear that such aspects of a hierarchical pattern as the exact following of a system of goals are connected with achieving high results and are of great significance (Van Hooft, Wanberg \& Hoye, 2013). With that in mind, it can be said that, based on the obtained empirical data, the characteristics of the psychological qualities of the managers from the enterprises with the market-hierarchical OC most nearly fulfill the requirement of achieving high-quality work results. In the hierarchical OC model the manager requires weakly work-motivated employees to reach certain goals, while the clan-hierarchical OC suggests that managers require employees to reach the same goals but with the condition that they maintain a more or less comfortable work life. Such managers support their subordinates by informal care of their psychological well-being. In both cases the issue is neither about the employees' understanding of the goal and clear ways to achieve it nor about raising the subjective involvement in work that provides attention, responsibility, self-control, and other psychological components of high efficiency. 
In the adhocratic OC with market elements the managerial situation is much better than in the clan-hierarchical OC, but the absence of strong cohesion between participation in the work process and its efficiency is noticed. The personnel, to a large extent, maintain the priority for out-professional self-identifications and, therefore, the orientation toward the realization of personal creativity at the expense of production efficiency. The market-hierarchical OC model, following the data from Table 2 , is the only one that gives priority to the professional, work-related self-identifications of mid-level managers. In this model they make open decisions, have clear and reasonable goals, encourage executive personnel accordingly, and demonstrate correct models of labor behavior in their leadership behavior.

Moreover, the study allowed us to identify significant differences in the management approaches to increasing the loyalty of personnel depending on the type of OC because it manifests the kind of philosophy that unites organizational values and certain management instruments aimed at modifying the values of personnel and their behavior patterns (Birdi, Clegg, Patterson, Stride, Wall \& Wood, 2008). A change of values is possible only through fostering the preferred behavior patterns, which manifest relevant values (Scott, Herbst \& Houmanfar, 2009).

For instance, we have found that in a hierarchical culture formal events prevail; they are manifested in different aspects of organizational life. Almost all organizational processes are strictly regulated, and formal rules and official policy and maintaining the smooth running of the enterprise are important; strict control over the work processes based on formal indicators (completion rate) is popular. In an OC with clan-component dominance, orientation toward recreation activities prevails: there are many traditions, corporate special events; employees typically gather outside work; a broad social package is provided irrespective of real efficiency. A wide range of social-engineering technologies is almost not used. In an OCs with a market orientation, the instruments of personnel management and social interaction change dramatically. They are oriented, to a large extent, toward involving employees in organizational life, including decision-making; finding ways to save costs; improving quality (Fullerton, McWatters \& Fawson, 2003; Bekarev \& Plotnikov, 2012); and finding a balance between market requirements and resources, including those of a psychological character. Employees of such enterprises are put into situations requiring self-determination of the strategy for achieving set goals. Therefore, self-control is popular in such organizations; the emphasis is on the personal responsibility of each employee. The system of corporate training focuses on strategic goals of the enterprise's development and has a project character. Managers are not acquainted with the model of “job's demands - resources" (Demerouti, Bakker, Nachreiner \& Schaufeli, 2001), but the organization of work oriented to real performance determines the kinship of their practice and a theoretical model. According to this model, the resources for work efficiency are contained in those physical, psychological, social, and organizational aspects of work that lead to achieving production goals and that subjectively weaken the labor requirements and physiological and psychological value of labor efforts connected with these requirements; this model stimulates personal growth, training, and development. In such a way, the management of enterprises that have been able to achieve real market business principles discover the ability to select and develop personnel for a competitive enterprise, using also the opportunities hidden in the corresponding type of OC. 


\section{Conclusions}

First, since the 1990s, the critical task for Russian enterprises has been to move from the administrative to the market-innovation model of development. These models differ significantly in their requirements for the personal characteristics of managers, including middle managers.

Second, this transition is accompanied by the emerging major variability of OCs, which attracts personnel with certain personality traits. In each type of OC there is a specific vision for an effective mid-level manager. Four psychological models of an effective manager were detected - Mentor, Dictator, Creator, Businessman - with particular peculiarities of their dominant individual values, social self-identifications, characteristics of the managerial decisions they make, organizational leadership, and working capacity.

Third, the identified complex sets of personal characteristics correspond to varying degrees with those that are the most relevant for meeting the challenges of organizational changes when moving toward the market-innovative type of OC. The most adequate are the qualities of a Businessman, while the least adequate are the Dictator characteristics.

Fourth, in the evaluation of the effectiveness of a manager of an enterprise, the correspondence of his/her personal traits to the characteristics of the OC prevailing in the company is a stronger factor than his/her agreement with the long-term goals of the company. Thus, top management in a way becomes hostage to the existing OC, within which it has to evaluate middle managers based on the example of the best ones in the context of the relevant type of OC. This procedure opens an opportunity to utilize such functions of $\mathrm{OC}$ as internal integration but prevents external adaptation, which in turn becomes a serious psychological obstacle in the development of the enterprise.

Fifth, the OC of an enterprise fosters benchmark personal traits and relevant behavior patterns, among other things, through the evaluation of the leadership team. This evaluation may cause and consolidate the supported traits in those staff members who possess character traits that are not required by a certain OC. For this reason, the promising direction of research today is the development of methodological support for the evaluation of the latent character traits of personnel.

Sixth, the most important task for the psychological support of the organizational development of enterprises could be the development of a criteria database for the evaluation of managers and the development of a management talent pool based on the market-innovative vector of development of an enterprise and relevant changes in the OC.

Seventh, considering the fact that we were not able to identify an enterprise with a market-innovative OC, the obtained data may reflect only particular trends and may require further elaboration.

\section{References}

Aksenovskaya, L.N. (2007). The order model of organizational culture. Moscow: Academic Prospect, Triksta.

Bass, B. (1998). Transformational leadership: Industry, military, and educational impact. Mahwah, NJ: Erlbaum. 
Bass, B., \& Riggio R.E. (2006). Transformational leadership. (2nd ed.). NJ.: Lawrence Erlbaum Associates, Inc. Mahwah.

Bekarev, A., \& Plotnikov, M. (2012). Problems of social engineering. Personality. Culture. Society, 1, 219-227.

Birdi, K., Clegg, C., Patterson, M., Stride, C., Wall, T., \& Wood, S. (2008). The impact of human resource and operational management practices on company productivity: A longitudinal study. Personal Psychology, 61, 467-501. doi: 10.1111/j.1744-6570.2008.00136.x

Cameron, K., \& Quinn, R. (1999). Diagnosing and changing organizational culture. Reading, MA: Addison-Wesley.

Carter, M.Z., Armenakis, A.A., Field, H.S., \& Mossholder, K.W. (2013). Transformational leadership, relationship quality and employee performance during continuous incremental organizational change. Journal of Organizational Behavior, 34, 942-958. doi: 10.1002/job.1824

Cuevas-Rodríguez, G., Cabello-Medina, C., \& Carmona-Lavado, A. (2014). Internal and External Social Capital for Radical Product Innovation: Do They Always Work Well Together? British Journal of Management, 25, 266-284. doi: 10.1111/1467-8551.12002

Glazjev, S.J. (2007). Perspectives for the Russian economy in conditions of global competition. Retrieved from: http://cyberleninka.ru/article/n/perspektivy-rossiyskoy-ekonomiki-v-usloviyah-globalnoy-konkurentsii

Gubanov, S.S. (2015). Systemic crisis and the choice of the way of development for Russia. Economic and social changes: Facts, trends, forecast, 2(38), 23-41.

Guimond S., Chatard A., \& Kang P. (2010). Personality, Social and Self-categorization. European Journal of Personality, 24(5), 488-492.

Demerouti, E., Bakker, A. B., Nachreiner, F., \& Schaufeli, W. B. (2001). The job demands-resources model of burnout. Journal of Applied Psychology, 86(3), 499-512. doi: 10.1037/00219010.86.3.499

Diamond, M. (1996). Innovation and diffusion of technology. A human process. Consulting Psychology Journal: Practice and Research, 48(4), 221-229. doi: 10.1037/1061-4087.48.4.221

Driving Global Corporate Alignment in Complex Organizations. (2006). A Position Paper from Meeting Professionals International's Global Corporate Circle of Excellence. Meeting Professionals International (MPI). Retrieved from https://www.mpiweb.org/CMS/uploadedFiles/Research_and_Whitepapers/GCCOE-Paper6-Final\%20Nov\%2013_06.pdf

Dryakhlov, N. (2011). Corporate culture and corporate efficiency. In Corporate culture: Problems and development tendencies in the world and in Russia (pp. 337-351). Moscow: Nauka.

Dyrin, S. (2006). The Russian model of personnel management in the conditions of an industrial enterprise. St. Petersburg: Piter.

Fullerton, R., McWatters, C., \& Fawson, C. (2003). An examination of the relationships between JIT and financial performance. Journal of Operational Management, 21, 383-404. doi: 10.1016/S0272-6963(03)00002-0

Hannah, S. T., Sumanth, J.J., Lester, P., \& Cavarretta, F. (2014). Debunking the false dichotomy of leadership idealism and pragmatism: Critical evaluation and support of newer genre leadership theories. Journal of Organizational Behavior, 35, 598-621. doi: 10.1002/job.1931

Hofstede, G. (1991). Cultures and organizations: Software of the mind. London: McGraw-Hill.

Karpov, A. V. (2003). The psychology of management. Moscow: Gardariki.

Klimov, E. A. (2004). Introduction to labor psychology. Moscow: Moscow University Press; Academia.

Kudrin, A., \& Gurvich, E. (2014). A New Growth Model for the Russian Economy. Issues of economics, 12, 4-36.

Kuhn, M. H., \& McPartland, T. S. (1954). An empirical investigation of self-attitudes. American Sociological Review, 19(1), 68-76. doi: 10.2307/2088175 
Leonova, A. (2013). Organizational psychology. Moscow: INFRA-M.

Locke, E. A. (1976). The nature and causes of job satisfaction. In M. D. Dunnette (Ed.), Handbook of industrial \& organizational psychology. (pp. 1297-1349). Chicago: Rand-McNally.

Medvedev, D. (2007). Welcome speech of the Russian President at the State Council Presidium meeting, "On measures of support for industry in the Russian Federation". Retrieved from http://www.kremlin.ru

Medvedev, D. (2013, September 27). The time of easy decisions has passed. Vedomosti.

Morgunov, E. (2010). Organizational culture: Unity or plurality. Personnel Management, 6, 26-30.

Mumford, M.D., \& Fried, Y. (2014). Give them what they want or give them what they need? Ideology in the study of leadership. Journal of Organizational Behavior, 35, 622-634. doi: $10.1002 /$ job. 1921

Plotnikov, M.V., \& Chilipenok J.J. (2012). Management for social interaction. Issues of Management Theory and Practice, 1, 72-81.

Putin, V. V. (2012, January 30). On our economic goals. Vedomosti.

Putin, V. V. (2014). Speech at the forum "Russia Calling!". Retrieved from http://www.ria.ru/ trend/_Putin_Russia_calling_02102013

Schein, E. (1992). Organizational culture and leadership: A dynamic view (2nd ed.). San Francisco, CA: Jossey-Bass.

Schmitt, N. (2014). Personality and Cognitive Ability as Predictors of Effective Performance at Work. Annual Review of Organizational Psychology and Organizational Behavior, 1, 45-65. doi: 10.1146/annurev-orgpsych-031413-091255

Scott, A., Herbst, S.A., Houmanfar, R. (2009). Psychological approaches to values in organizations and organizational behavior management. Journal of Organizational Behavior Management, 29 (1), 47-68. doi: 10.1080/01608060802714210

Shcherbakov, V., Sheromova, I., Polevaya, S., \& Parenko, M. (2003). Method of interhemispheric sensor asymmetry assessment. Patent no. 2198589.

Sisoev, V. (2003). E. Landolt test. Work capacity diagnostics. St. Petersburg: IMATON.

Tosti, D.T. (2007). Aligning the culture and strategy for success. Performance Improvement, 46(1), 21-25. doi: 10.1002/pfi.035

Unsworth, K.L., Dmitrieva, A., \& Adriasola, E. (2013). Changing behavior: Increasing the effectiveness of workplace interventions in creating pro-environmental behavior change. Journal of Organizational Behavior, 34, 211-229. doi: 10.1002/job.1837

Van Hooft, E., Wanberg, C., \& Hoye, G. (2013). Moving beyond job search quantity: Towards a conceptualization and self-regulatory framework of job search quality. Organizational Psychology Review, 3(1), 3-40. doi: 10.1177/2041386612456033

Zakharova, L. N. (2008). Psychological stereotypes in management as barriers to the socialeconomic development of Russia. Problems of Management Theory and Practice, 2, 90-96.

Zakharova, L. N. (2009). The psychology of management. Moscow: Universitetskaya Kniga, Logos.

Zakharova, L. N. (2010). Psychological barriers to the innovative economy establishment. Social Work Psychology. Theory and Practice, 2, 313-330.

Zakharova, L., \& Leonova I. (2012). Value conflict management as a resource of organizational development. Issues of Management Theory and Practice, 11-12, 147-157.

Original manuscript received June 11, 2014 Revised manuscript accepted May 20, 2015

First published online September 30, 2015 